\title{
PENDEKATAN SUFISTIK DALAM PENDIDIKAN ISLAM BERWAWASAN PERDAMAIAN
}

\author{
A. Gani \\ Uiniversitas Islam Negeri Raden Intan Lampung \\ Jl. Letkol H. Endro Suratmin, Kota Bandar Lampung, Lampung 35131 \\ E-mail: musafirizzaabidin@gmail.com
}

\begin{tabular}{c|c|c}
\hline Received: & Revised: & Approved: \\
18/10/2018 & $25 / 11 / 2018$ & $25 / 11 / 2018$ \\
\hline
\end{tabular}

DOI: http:/ / dx.doi.org/10.32332/akademika.v23i2.1239

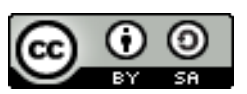

Pendekatan Sufistik dalam Pendidikan Islam Berwawasan Perdamaian Licensed Under a Creative Commons Attribution-ShareAlike 4.0 International License

\begin{abstract}
Conflict becomes part of contemporary phenomena that embraces all dimensions of human life, starting from the level of individuals, society, to relations between countries. Conflict in all of its variety, both economic, political conflicts, even conflicts between civilizations, cannot be separated from the "on-name" religion. Islam which teaches love and peace is distorted into Islam that teaches conflict. Islamic education in a broad context is responsible for the formation of logical thinking of humans who like to spread terror and conflict. This paper examines how the Sufism approach in Islamic education plays its part as the Islamic tradition that teaches Islam in the form of love and spreads Peaceful Islam and has A peace of mind with research Library research that uses qualitative descriptive analysis techniques with the results of research that is mystical approach in Islamic education fundamental alternatives in order to reduce conflict and bring peace.
\end{abstract}

Keywords: Education, Islam, Peace, and Sufism. 


\begin{abstract}
Abstrak
Konfik menjadi bagian dari fenomena kontemporer yang melanda seluruh dimensi kehidupan manusia, mulai dari tingkat individu, masyarakat, sampai hubungan antar negara. Konflik dalam ragam rupanya, baik konflik ekonomi, politik, bahkan konflik antar peradaban, tidak bisa dilepaskan dari "atas-nama" agama. Islam yang mengajarkan cinta kasih dan perdamaian didistorsi menjadi Islam yang mengajarkan konflik. Pendidikan Islam dalam konteks yang luas bertanggungjawab atas terbentuknya nalar berpikir manusia yang suka menebar teror dan konflik. Tulisan ini mengkaji tentang bagaimana pendekatan sufisme dalam pendidikan islam menjadi bagian dari tradisi Islam yang mengajarkan Islam dalam rupa cinta kasih dan menebarkan Islam Damai dan berwawasan perdamaian dengan jenis penelitian Library research yang menggunakan teknik analisis deskriptif kualitatif dengan hasil penelitian yaitu pendekatan sufistik dalam pendidikan Islam adalah alternatif fundamental dalam rangka mengurangi konflik dan mewujudkan perdamaian bangsa. Salah satu teladan prakteknya dapat dilihat dari ulama-ulama Nusantara.
\end{abstract}

Kata Kunci: Pendidikan, Islam, Perdamaian, and Sufisme.

\title{
A. Pendahuluan
}

Semua agama mengajarkan cinta, kasih sayang, kebajikan, kedamaian, persaudaraan dan sejumlah niai-nilai kemanusiaan secara ideal dan normative. ${ }^{1}$ Namun, sejarah mencatat agama tidak selalu positif untuk kemanusiaan. Kadang kala agama memunculkan banyak problem. Terorisme, ekstrimisme, radikalisme dan fundamentalisme menghiasi ruang publik "atas-nama" agama. Islam sering kali disebut-sebut menjadi motiv utama gerakan mereka, dan di sinilah pro kontra itu dimulai. Sebab, Islam adalah agama damai, dan begitulah yang dipahami oleh mayoritas. ${ }^{2}$

Aksi brutal anti-kemanusiaan ini membuat dunia pendidikan Islam mendapat sorotan penting. Mental spiritual merosot, dan umat muslim terjerumus dalam jurang perpecahan, konflik, saling hujat, takfir (mengkafirkan kelompok yang berbeda). Dunia pendidikan Islam menghadapi apa yang dikategorikan sebagai dehumanisasi pendidikan dan nilai-nilai spiritual agama. Penelitian pakar Barat pun menyudutkan

${ }^{1}$ Nathanael Emmons and Jacob Ide, Systematic Theology (Bonston: Crocker\& Brewster, 1842), 178.

${ }^{2}$ E. O’Ballance, Islamic Fundamentalist Terrorism (The Iranian Connection, 1979), 73. 
lembaga pendidikan Islam, seperti Madrasah, dan menghubungkan lembaga-lembaga pendidikan Islam ini dengan jaringan terroisme. ${ }^{3}$

Berbagai fenomena terorisme, radikalisme, fundamentalisme yang mengatasnamakan Islam menyebabkan sejarah kelahiran Islam dilupakan. Pada awal kelahirannya, Islam muncul sebagai bentuk respon terhadap masyarakat "jahiliyah", dengan membawa prinsip-prinsip kesetaraan, kemerdekaan serta penghormatan terhadap hak-hak asasi manusia (human right). Islam memperjuangkan kembali nilai-nilai kemanusiaan yang diabaikan. Al-Qur'an menjadi saksi atas sikap Islam sebagai agama cinta kasih, toleran atas perbedaan keyakinan dan agama, serta anti kekerasan. ${ }^{4}$ Tidak satupun dalam Piagam Madinah yang mendorong umat muslim melakukan teror, baik kepada sama umat muslim maupun orang kafir yang sudah berdamai. Piagam Madinah adalah simbol bahwa Islam itu mengusung semangat bersepakat untuk berbeda. ${ }^{5}$

Dimensi spiritual Islam yang paling menarik adalah tasawufsufisme. Dalam kehidupan modern, sufisme layak sebagai mediator bagi terciptanya masyarakat multi agama yang rukun. Dalam kajian kontemporer, sufisme terbukti aktif untuk mempopulerkan pendekatannya sendiri, yang kompatibel dengan pluralisme, demokrasi, toleransi, koeksisntensi. ${ }^{6}$ Ajaran kedamaian, cinta, kasih dan sayang dalam sufisme adalah aspek-aspek yang paling sering disuarakan untuk mendialogkkan Islam dengan kebutuhan hidup komtemporer, khususnya di saat pentas dunia dipenuhi oleh perang, pembunuhan, dan penindasan. Kaum Sufi memiliki cara mereka sendiri dalam mengajarkan Islam yang penuh cinta kasih.

Dalam satu periode Islamisasi di Nusantara, kecenderungan sufistik juga turut mewarnai. Kelompok-kelompok tarekat bermunculan, dan Islam yang lahir dari pesantren semakin menyebar pesat dibanding sebelumnya. Karya-karya sastra dan suluk-suluk Jawa yang memiliki kecenderungan wujudiyah diciptakan, dan turut memperkaya khazanah intelektual Islam Sufistik di Tanah Nusantara. Syair-syair Hamzah Fansuri menandai kegemilangan islam sufistik di tanah Jawa ini. Bahkan,

\footnotetext{
${ }^{3}$ Wolfram Weisse dan Inga Niehaus, Muslim School and Education in Europe and South Africa, (Munster: Waxmann, 2011), 73.

${ }^{4}$ N.K. Singh, A Religion of Peace (Global Vision, 2002).

${ }^{5}$ Tudor Rose, Agree to Differ (France: UNESCO Publishing, 2015), 151.

${ }^{6}$ Mamadou Diouf, Tolerance, Democracy, and Sufis in Senegal, (New York: Columbia University Pres, 2013), 26-27.
} 
para pakar mengatakan bahwa penyebaran pesantren berkaitan dengan institusionalisasi pemikiran sufistik ini, yang berlandaskan pada kesetiaan murid pada mursyid ${ }^{7}$.Alhasil, pendidikan berbasis pendekatan sufistik memiliki dasar embrionya dalam sejarah kebangsaan kita. Sebaliknya, radikalisme dan fundamentalisme agama, terorisme dan ekstrimisme, terbukti gagal diterapkan di tengah kultur bangsa yang pluralis, majemuk dan hidup dengan semangat gotong-royong.

Sebelumnya terdapat beberapa penelitian yang mengkaji tentang sufisme, Pertama,Paradigma Sufistik Tafsir Al-Qur'an Bediuzzaman Said Nursi dan Fethullah Gulen oleh Ah. Fawaid dengan hasil penelitian yaitu Paradigma sufistik yang dikembangkan Nursi dan Gulen tidak sepenuhnya menjinakkan akal di samping hati dan jiwa. Ketiga-tiganya digunakan secara seimbang dalam mengarungi samudera Al-Qur'an. Selain itu, apa yang dilakukan Nursi, dan khususnya Gulen, sekaligus membantah apa yang diragukan Ignaz Goldziher bahwa tasawuf meru-pakan doktrin asing dari tradisi Islam. Baik Nursi maupun Gulen merupakan tokoh yang lebur bersama komunitasnya, sehingga cakrawala tafsir yang dihasilkan le-bih bernuansa populis, ketimbang perdebatan akademis. Kedua, Pemikiran Sufistik Syaikh Umar Ibn Al-Fâridh dalam Dîwân Ibn Al-Fâridh oleh Idrus Al-Kaf ${ }^{8}$. artikel ini difokuskan pada upaya memahami tema-tema alhubb al-ilâhi dalam pemikiran sufistik Syaikh Umar ibn al-Farîdh. Ketiga, dakwah islamiyah dengan pendekatan sufistik oleh Fathul Mufid ${ }^{9}$ dengan hasil penelitian yaitu Tujuan dakwah sufistik tidak hanya sebataskearifan individual atau melakukan ritual-ritual mistik dan cenderung lebih mengedepankan hubungan terhadap Tuhan dan Rasulnya, tetapi juga, yang terpenting, mengedepankan kesalehan secara universal atau sosial.

Penelitian menyebutkan bahwa Islam Sufistik mendominasi keberislaman Nusantara tidak saja datang dari ilmuan dalam negeri, tetapi juga diamini oleh pakar asing, salah satunya teori dari A.H. Johns, yang mengatakan bahwa Islam Nusantara lebih bercorak sufistik. Dari sana lahirlah tokoh-tokoh sufi besar seperti Nuruddin ar-Raniri, Hamzah

\footnotetext{
${ }^{7}$ Jimly As-Shiddiqie, Bang Imad: Pemikiran dan Gerakan Dakwahnya, (Jakarta: Gema Insani Press, 2002).

${ }^{8}$ Idrus Al-Kaf, "Pemikiran Sufistik Syaikh Umar Ibn Al-Fâridh dalam Dîwân Ibn AlFâridh" 20, no. 1 (2014): 23.

${ }^{9}$ Fathul Jannah, "Pendidikan Islam Dalam Sistem Pendidikan Nasional" 13, no. 2 (2013): 13 .
} 
Fansuri, Abd ar-Rauf as-Sinkili, Muhammad Yusuf al-Maqassari, dan sejumlah tokoh Wali Songo di Jawa. ${ }^{10}$ Keempat, Epistemologi Corak Tafsir Sufistik oleh Lenni Lestari, Banyak interpretasi ideologi al-Qur'an telah dikembangkan hingga saat ini. Salah satunya adalah interpretasi mistis (sufistik). Artikel ini akan mengeksplorasi tentang aspek epstemologi penafsiran mistik dan a sedikit sejarah dalam pemetaan besar tafsir alQur'an. Pada bagian akhir artikel ini akan dijelaskan tentang bagaimana interpretasi mistisisme harus dihadapi dengan ayat-ayat (ayat) terkait dengan Fiqih, Sains, Budaya, dan sebagainya. dengan hasil penelitian yaitu Corak tafsir sufi terbagi menjadi dua, yaitu al-tafsir sufi nazari dan al-tafsir alsufi al-Isyari. Al-tafsir sufi nazari adalah tafsir yang berpegang pada metode simbolis yang tidak berhenti hanya pada aspek kebahasaan saja. Sedangkan Al-tafsir al-sufi al-Isyari menurut al-Zahabi adalah mentakwilkan ayat-ayat al-Quran yang berbeda dengan maknanya yang dzahir berdasarkan isyarat (petunjuk) khusus yang diterima oleh para ahli sufi. Sumber penafsiran corak tafsir sufi adalah intuisi dan filsafat. Pendekatan yang digunakan adalah takwil. Metode yang digunakan adalah tahlili. Sedangkan validitas penafsiran cenderung pada penguasa yang ada saat itu dan teori keilmuan mufassir. Kelima, Dakwah Islamiyah Dengan Pendekatan Sufistik oleh Fathul Mufid artikel ini difokuskan pada Dakwah Islamiyah yang semestinya diharapkan mampu memberikan solusi berbagai masalah hidup saat ini, ternyata lebih dipahamihanya sekedar memenuhi perintah secara normatif, sehingga dirasa kurang menyentuh ajaran Islam secara substantif. Dakwah Islamiyah mengalami reduksi sebagai pola pendekatan ritual, simbol-simbol, dan memisahkan antara kehidupan dunia dan akhirat, serta belum menyentuh pada ranah penghayatan agama. Akibatnya, nilai-nilai wahyu terpisah dari pribadi umat Islam yang lebih mengandalkan kekuatan rasional semata. Keadaan ini menimbulkan kecenderungan keberagamaan yang tidak memiliki dimensi Ilahiyah. Oleh sebab itu, alternative dakwah sufistik menjadi penting bagi dakwah Islamiyah untuk dilihat kembali sebagai bagian integral dari ajaran Islam, karena dalam dakwah sufistik, ranah IQ (żaka'aqli), EQ (żaka żihni), dan SQ (żaka qolbi) merupakan komponen-komponen yang dikembangkan secara harmonis. Pengertian sufistik adalah hal-hal yang berkenaan dengan ilmu tasawuf. Istilah sufistik mengacu kepada sifat, seperti pemikiran sufistik yang berarti pemikiran yang bernuansa

${ }^{10}$ Madarzuki Wahid dan Rumi, Figh Madzhab Negara: Kritik atas Politik Hukum Islam di Indonesia (Yogyakarta: LKiS, 2011), 100. 
tasawuf yang tujuan puncaknya adalah mendekatkan diri kepada Allah dengan menggunakan pendekatan hati, bukan logika. Hal ini karena tasawufberpandangan bahwa kebenaran yang dihasilkan oleh akal dan penalaran adalah sangat terbatas, sedangkan kebenaran yang diperoleh melalui ma'rifah adalah segala-galanya, karena diperoleh melalui penglihatan mata hati yang mendapat sinar Ilahi. Dakwah sufistik adalah model dakwah yang bisa membuat mad'u memiliki sifat-sifat mulia, bukan sekedar kognisi, tetapi lebih pada ranah afeksi atau aspek kesadaran. Tujuan dakwah sufistik tidak hanya sebatas kearifan individual atau melakukan ritualritual mistik dan cenderung lebih mengedepankan hubungan terhadap Tuhan dan Rasulnya, tetapi juga, yang terpenting, mengedepankan kesalehan secara universal atau sosial. Perbedaan penelitian sebelumnya membawa penulis untuk melakukan penelitian tentang pendekatan sufistik dalam pendidikan islam berwawasan perdamaian bangsa. Penelitian ini menggunakan teknik analisis deskriptif kualitatif dengan jenis penelitian Library research.

\section{B. Islam Cinta dalam Sufisme}

Perkembangan Islam tidak dapat dipungkiri berkaitan erat dengan kaum Sufi. Bahkan, bagi panganjur dan pengamalnya, Islam itu adalah sufisme, yang diambil langsung dari Rasulullah dan praktek para sahabat Nabi. ${ }^{11}$ Sementara itu, sufisme itu sendiri tidak bisa dipisahkan dari ajaran esoterik, yang lebih mengedepankan substansi daripada formalitas, yang menyikapi berbagai masalah keagamaan dan keberagamaan dengan caracara lemah lembut. ${ }^{12}$ Dakwah Islamiyah dengan pendekatan sufistik selalu saja berlangsung dengan damai, khususnya dalam konteks Indonesia. ${ }^{13}$

Sufisme merupakan ikhtiar meningkatkan kualitas diri menjadi pribadi yang unggul (khaira ummah). Nilai-nilai yang diajarkan seperti kesabaran, optimisme, dan keikhlasan. Ajaran yang menekankan pembersihan diri ini dapat merubah manusia menjadi lebih baik, penuh cinta kasih dan semakin dekat kepada Allah Swt. Pendidikan yang ditekankan dalam komunitas sufistik ditujukan untuk mencetak pribadi muslim yang berakhlak mulia sesuai dengan yang dicontohkan oleh Rasulullah Saw.

${ }^{11}$ Jean Louis Michon dan Roger Gaetani, Sufism: Love $\mathcal{E}$ Wisdom (Indiana: Worl Wisdom Inc., 2006), 28. 30.

12 Titus Burckhardt, Introduction to Sufi Doctrine (Indiana: World Wisdom, Inc., 2008),

${ }_{13}$ Azyumardi Azra, Islam in the Indonesian World an Account of Institutional Formation (Bandung: Mizan, 2006), 53. 
Teknik-teknik pengajaran, misal seorang murid meneladani syeikh, pun juga bertujuan untuk meneladani Rasulullah saw.

Islam dalam Sufisme ditampilkan sebagai Islam yang menjunjung tinggi moralitas (akhlaq). Tujuan akhir berbagai dimensi esoterik (batiniyah) pada diri seorang manusia, yang menjadi objek kajian sufistik, adalah mencapai pribadi yang luhur. Orang yang sudah memahami dan mengamalkan ajaran sufisme tidak akan berani melakukan kedzaliman atau kerusakan sekecil apapun di muka bumi ini. Kezhaliman adalah dosa besar yang bisa mengotori hati dan dimensi batin seseorang. Kebersihan batin dikedepankan daripada kebersihan lahiriah. Batiniyah akan mempengaruhi yang lahiriah. ${ }^{14}$

Namun begitu, Harun Nasution berpendapat bahwa ajaran Islam yang dominan saat ini justru fikih. Dominasi fikih atas sufisme Islam ini memberikan gambaran yang "pincang" tentang keutuhan dimensi ajaran Islam. ${ }^{15}$ Karenanya, porsi ajaran sufisme perlu ditambah dalam pengajaran dan pendidikan Islam yang berlangsung di lembaga-lembaga pendidikan agama Islam, sekolah agama maupun sekolah umum, termasuk di pondok-pondok pesantren. Banyak analisa dari berbagai riset akademik mulai melirik pentingnya memasukkan akhlak tasawuf ke dalam sistem kurikulum pendidikan kita. ${ }^{16}$

Dunia pendidikan dinilai penting mengambil bagian besar dari ajaran Sufisme Islam lantaran Sufisme mengajarkan penghargaan terhadap sesama makhluk Allah SWT, tanpa membedakan latar belakang agama, status sosial, suku dan sebagainya. Ajaran sufisme dengan dosis tinggi (yang tidak lagi akhlaqi, melainkan falsafi) menggiring umat pada sikap toleran dan menjunjung perdamaian. Sufisme yang toleran macam ini memiliki geneologi atau setidaknya bersentuhan dengan konsep wahdah al-wujud Ibn 'Arabi. Asghar Ali Enginer menuturkan bahwa sufi yang menganut paham wahdah al-wujud dapat bergaul leluasa dengan semua orang tanpa melihat latar belakangnya. ${ }^{17}$

${ }^{14}$ A.J. Berry, Sufism: An Account of the Mystics of Islam (Oxon: Routledge, 2013), 44.

${ }^{15}$ Harun Nasution, "Teologi Islam; Aliran-aliran Sejarah Analisa Perbandingan" (Jakarta: UI Press, 1986).

${ }_{16}$ Muhammad Sholikhin, Sufi Modern: Mewujudkan Kebahagiaan, Menghilangkan Keterasingan, (Jakarta: Elex Media Komputindo, 2013), t.t., 220.

${ }_{17}$ Asghar Ali Enginer, Islam dan Teologi Pembebasan (Yogyakarta: Bentang Pustaka, 2000), 297. 
Wahdah al-wujud atau the oneness of being adalah konsep yang mengajarkan bahwa keragaman merupakan tajalli keindahan asma dan sifat-sifat ilahiah. Sebagai konsekuensi dari tajalli Tuhan Yang Tungga maka sejatinya realitas plural ini pun adalah tunggal. ${ }^{18}$ Sangatlah mungkin apa yang Asghar Ali Enginer katakan adalah benar, mengingat wujud yang beragam itu adalah tunggal. Sehingga membenci, merusak, membunuh atau bahkan mengadakan perang adalah perbuatan yang tidak bisa dibenarkan secara ontologis. Dengan kata lain, sikap paling layak menyikapi keragaman realitas adalah cinta kasih pada sesama makhluk Tuhan. ${ }^{19}$

Syeikh Nawawi al-Bantani, “Janganlah kalian memandang seseorang dengan pandangan merendahkan dan menghinakan, meskipun ia seorang musyrik, karena khawatir akan berdampak padamu. Bisa saja, ma'rifah-mu (pada Allah) terampas, padahal ia bisa memberikannya." ${ }^{20}$ Ajaran-ajaran cinta kasih dan damai seperti ini diperlukan oleh lembagalembaga pendidikan Islam dan pondok-pondok pesantren. Dalam tradisi pesantren, rujukan kitab-kitab tasawuf masih terbatas pada Imam al-Junaid al-Baghdadhi, al-Qusyairi, dan Imam al-Ghazali. ${ }^{21}$ Sedangkan kajian atas ajaran sufistik dari Ibnu 'Arabi, Jalaludin Rumi, al-Jili, al-Busthami, masih terbatas dan belum massif.

Dengan bermodal ajaran Islam yang rahmatan li al-'alamin, umat Islam mempunyai potensi besar untuk membangun persaudaraan lintas iman (ukhuwwah imaniyyah), sebagai embrio terciptanya perdamaian dunia (world peace). Bahkan, umat muslim perlu menyempurnakan iman dan islam mereka dengan ihsan, dimana nafas ihsan ini adalah sufisme itu sendiri. Dengan belajar, mengajarkan dan mengamalkan ajaran sufisme, individu diharapkan mampu memanifestasikan sifat-sifat ilahiyah di muka bumi, yakni manusia yang mencintai seluruh entitas, membangun kehidupan yang damai, dan membangun peradaban yang adi luhung. Inilah pribadi Insan Kamil yang dicita-citakan Islam Sufistik. ${ }^{22}$

\footnotetext{
${ }^{18}$ Sayyed Hossein Nasr, The Garden of Truth (Bandung: Mizan, 2010), 59.

19 A.J. Berry, Sufism: An Account of the Mystics of Islam.

${ }^{20}$ Muhammad Nawawi al-Bantani, al-Futuhat al-Madaniyyah (T.Th.), t.t., 21-22. 2008), 52.

${ }^{21}$ Sokhi Huda, Tasawuf Kultural: Fenomena Shalawat Wahidiyah (Yogyakarta: LKIS,

${ }^{22}$ Toshihiko Izutsu, Sufism and Taoism: A Comparative Study of Key Philosophical Concepts (California: University of California Press, 1984), 18-19.
} 
Dalam sebuah syair yang gemilang, Hamzah Fansuri mengatakan: Satukan hangat dan dingin/tinggalkan juga loba dan ingin/hancurkan hendak seperti lilin/mangkanya dapat kerjamu licin.

Mustahil nalar non-sufistik mampu mengatasi kategori-kategori dan melihat segala keragaman adalah satu wujud, yaitu wujud yang tunggal. Hangat dan dingin adalah dua kategori yang saling menegasikan, diman keduanya mustahil bersatu. Tetapi, di tangan para salik, pelaku sufisme, panas/hangat dan dingin dapat bersatu. Hal itu hanya bisa apabila loba dan keinginan telah hancur, dan hati hanya menjadi wadah menampung luberan tajalli Allah. Hamzah Fansuri telah menegaskan, mangkanya dapat kerjamu licin, yaitu bahwa pekerjaan semacam itu sangatlah sulit, tidak semua kaki mampu menapaki, dan boleh saja mudah tergelincir.

Syair lain Hamzah Fansuri yang mengagumkan saat bicara tentang Tuhan dan pencarian kebenaran berbunyi: Hamzah Fansuri di dalam Mekkah/ Mencari Tuhan di Baitul Kakbah/Di Barus ke Kudus terlalu payah/Akhirnya dapat di dalam rumah. Spirit-spirit islam sufistik yang lebih mencintai pencarian jati diri, menghargai indigenusitas keislaman, kenusantaraan, sudah terlihat dalam syair-syair ulama nusantara. ${ }^{23}$

Apa yang dilakukan Hamzah Fansuri melalui syair-syairnya, dilakukan pula oleh Abdur Rauf as-Singkili, yang lahir di Singkel, Aceh Selatan. Islamisasi yang dilakukan oleh beliau dilakukan dengan cara-cara damai, lemah lembut, penuh kebijaksanaan. Islam yang diajarkan oleh Abdurrauf as-Singkili tidak membawa spirit perlawanan terhadap bangsa asing, dan tidak pula bersikap dingin. Islam masuk dengan jalan damai dan bersahabat. ${ }^{24}$

\section{Pendidikan Islam Sufistik}

Dalam Kajian Keislaman, ada lima hal yang harus dijaga dan dipelihara. Kelima hal tersebut menjadi maqashid syar'iyah, yaitu tujuantujuan agama. Maqashid Syar'iyah ini terdiri dari: perintah menjaga agama (hifdzal-din), menjaga jiwa (hifdzal-nafs), menjaga akal (hifdz al-'ql)

${ }^{23}$ Titus Burckhardt, Introduction to Sufi Doctrine.

${ }^{24}$ Muhammad Hisyam Kabbani, Tasawuf dan Ihsan, terj. Zaimul Am (Jakarta: Serambi, 2007). 
menjaga keturunan (hifdz al-nasl), dan menjaga harta (hifdz al-mal). ${ }^{25}$ Lima hal tersebut menjadi perinsip agar supaya kehidupa di dunia ini tetap berlangsung dengan baik sesuai tuntunan agama Islam. Pribadi yang Kamil seperti dicita-citakan kaum Sufi tidak akan melakukan destruksi, sebab destruksi bertentangan dengan maqashid syar'iyah.

Pendidikan Islam yang bernalar sufistik mendambakan kehidupan bermasyarakat, berbangsa dan bernegara yang rukun. Output pendidikan Islam Sufistik adalah realisasi dan ekternalisasi ajaran-ajaran damai Islam, ditandai kemampuan hidup rukun dan berdampingan dengan orang-orang lain yang berbeda agama, beda ideologi, beda etnis,dan beda budaya.Sebab, perbedaan merupakan hukum alam (sunnatullah) sebagai Tajalli Allah swt, yang tidak bisa dipisahkan dalam kehidupan sehari-hari. Sufisme Islam mengajak para salik untuk menerima perbedaan ini sebagai tajalli atau manifestasi dari seluruh keindahan sifat dan asma Allah swt. ${ }^{26}$

Sufisme Islam menyadari betul secara moril bahwa manusia adalah "makhluk sosial" yang saling membutuhkan satu sama lain, dimana tidak ada seorangpun bisa hidup sendirian. Namun, pengertian ini tidak sekuler seperti rumusan sains sosial dari Barat yang lebih akrab dengan istilah zoon politikon. Manusia sebagai makhluk sosial adalah interpretasi dan translasi atas sifat Allah Yang Maha Esa (al-Ahad al-Wahid) lagi Maha Berdiri Sendiri (al-Qayyum).Keyakinan teologis ini memiliki konsekuensi sosiologis, yaitu bahwa tidak ada manusia yang mampu berdiri sendiri, dan oleh karenanya, manusia bergantung pada sesamanya secara idhafi dan bergantung hanya pada Allah as-Shomad secara hakiki.

Pendidikan Islam Sufistik akan selalu menekankan kebergantungan penuh pada Allah dan cinta kasih kepada sesama. Islam Sufistik mengarahkan para murid dan salik untuk mencintai dan menghargai orang lain, terlebih saat terjadiberbagai macam persinggungan, mulai dari persinggungan bahasa, budaya, hingga persinggungan agama. Kebersinggungan meniscayakan sikap saling memahami dan saling menerima eksistensi orang lain. Menerima kehadiran orang lain yang berbeda adalah akar filosofis spiritual untuk kemudian memicu sikap saling

${ }_{25}$ Yusuf Ahmad Muhammad al-Badawi, Maqashid al-Syariah inda Ibn Taymiyah (Yordania: Dar al-Nafais, 1999), 127.

${ }^{26}$ Ahmad Thib ibn al-Basyir, Kitab al-Hikam al-Musamma an-Nafs al-Rahmani fi al-Thur al-Insani (Beirut: Dar al-Kutub al-Ilmiah, 2014), 221. 
menghargai, menghormati, menyayangi dan menerima "yang-lain". Sebab, diri sendiri maupun orang lain sama-sama tajalli Allah swt.

Spirit Pendidikan Islam Sufistik adalah pengamalan atas firman Allah swt, "hai manusia, sesungguhnya Kami menciptakan kalian dari seorang laki-laki dan seorang perempuan, lalu menjadikan kalian berbangsa-bangsa dan bersuku-suku agar saling mengenal..." (Qs. AlHujurat: 13). Orang yang berbeda keyakinan, berbeda bahasa, etnis, dan budaya tetaplah manusia yang harus dihormati, dihargai, dan diterima keberadaannya.Perbedaan adalah sunnatullah yang mengandung hikmah besar, yaitu untuk saling mengenal satu sama lain. ${ }^{27}$

Contoh pendidikan sufistik seperti ini dicontohkan oleh Sunan Kalijaga, salah satu anggota Wali Songo. Sunan Kalijaga menghadirkan Seni Wayang untuk menyajikan kata-kata mutiara bernafas Islami, mengajak meditas, memberikan pendidikan pengetahuan, menyuguhkan hiburan. Bahkan, Seni Wayang dapat ditarik menjadi seni tarik suara (bernyanyi), seni lukis dan ukir.

Islamisasi dengan teknik seni seperti ini, Sunan Kalijaga dan para Wali Songo lainnya mengajarkan teknik berdawah yang mengedepankan perdamaian antar golongan,jalan toleransi, dan kesanggupan untuk memberikan ruang eksistensi bagi "yang-lain".Islam tampil lebih menghibur daripada berwajah garang. Pendidikan Islam Sufistik sejatinya adalah konsep tentang pembentukan pribadi manusia yang sejalan dengan sunnatullah, yaitu pribadi yang berwawasan luas, merangkul seluruh golongan, dan memberi ruang ekspresi dan eksistensi bagi "yang-lain" (Qs. Al-Hujurat: 13).

Selain berhubungan dengan manusia, Pendidikan Islam Sufistik juga mengatur hubungan antara manusia dan alam.Hablun min al-'alam ini diaplikasikan dengan menjaga kelestarian alam, tidak menebang pohon sembarangan, tidak membakar hutan dan menjaganya agar tetap hijau, tidak membuang sampah sembarangan, menjaga kebersihan sebagai bagian dari iman.Hablun min al-'alam dapat juga diterjemahkan menjadi

${ }^{27}$ Sering kali, para pembenci sufisme memfitnah sufisme Islam itu bagian dari Hinduisme, yang coba menyatukan agama-agama. Misinterpretasi seperti ini banyak dilakukan yang ditandai dengan karya-karya akademik. Contohnya, Ibnu Arabi dinilai sebagai tokoh sufi yang membangun asas-asal falsafinya di India. Lihat Mani' ibnu Hammad al-Juhni, al-Mawsu'ah al-Muyassarah fi al-Adyan wa al-Madzahib wa al-Ahzab al-Mu'ashirah, 4 ed. (Riyadh: Dar al-Nadwah al-Alamiyah, 1420), 994. 
kesanggupan diri menjaga lingkungan, melestarikan keberlangsungan hidup,baik kehidupan manusia, hewan-binatang, maupun tetumbuhan. ${ }^{28}$

Penghargaan Islam atas keberlangsungan hidup tercermin dalam setiap tindak tanduk Rasulullah saw sebagai suriteladan umat muslim. Sejarah mencatat bahwa Rasulullah SAW tidak melaksanakan perang, karena perang bersifat merusak. Jika perang terpaksa dilakukan maka sifat-sifat destruktif dilarang. Sebab, apabila perang tetap dilakukan maka kerugian tidak saja pada kedua belah pihak yang terlibat perang melainkan pihak-pihak tak bersalahpun terancam menjadi korban, seperti kerusakan pada medan tempat perang tersebut diselenggarakan. Rasulullah saw melarang menimbulkan kerusakan. Bahkan, dalam sebuah sabdanya, Rasulullah saw melarang membunuh binatang dan menebang pohon. Dalam kondisi perang pun, umat muslim dilarang membunuh wanita, orangtua lanjut usia, dan anak-anak. ${ }^{29}$

Pendidikan Islam Sufistik ingin mengembalikan Islam pada akar katanya, yaituaslama-yuslimu-islaman.Dalam perspektif linguistik pun, Islam mengandung makna ketundukan, kepasrahan, dan penyerahan diri. Ini berarti segala sesuatu, baik pengetahuan, sikap, perilaku maupun gaya hidup,harus menunjukkan ketundukan dan kepatuhan terhadap kehendak Allah. ${ }^{30}$ Kepatuhan adalah antidot dari egoisme. Kepasrahan adalah antitesa atas sentralisme. Sedangkan egoisme dan sentralisme adalah sumbersumber yang melahirkan absolutisme. Puncaknya, absolutisme menggoda untuk melahirkan sikap "menang sendiri", "negasi atas yang-lain", dan penolakan keberagaman.

Islam Sufistik tampak sebagai narasi tandingan atas fenomena kontemporer dimana Islam ditampilkan sebagai ketundukan pada ambisi, kekuasaan dan kekuatan. Terrorisme, radikalisme, fundamentalisme, ekstrimisme, dan citra negatif lainnya yang disematkan pada Islam oleh non-muslim dan terjadi perpecahan di tubuh umat muslim sendiri, adalah bentuk-bentuk konsekuensi logis dari anti-keberagaman. Sehingga, Islam ditampilkan berwajah keras penuh teror, dan kelompok-kelompok teroris

${ }^{28}$ Moch Eksan dan Kiai Kelana, Biografi Kiai Muchith Muzadi (Yogyakarta: LKIS, 2000), 132.

29 Amanullah Halim, Buku Putih Kaum Jihadis: Menangkal Ekstrimisme Agama dan Fenomena Pengafiran (Tangerang: Lentara Hati, 2015), 299.

${ }^{30}$ Khaled Abou El Fadhl, Selamatkan Islam dari Muslim Puritan (Jakarta: Serambi, 2006), 155. 
ini menebar perang dengan mengatasnamakan diri mereka sebagai pejuang nilai-nilai Islam. ${ }^{31}$

\section{Spirit Perdamaian Sufistik}

Dalam sebuah syair berjudul Syair Perahu, Hamzah Fansuri mengatakan: "...Wahai muda, kenali dirimu/ialah perahu tamsil tubuhmu/tiadalah berapa lama hidupmu/ke akhirat jua kekal dirimu/hai muda arif budiman/hasilkan kemudi dengan pedoman/alat perahumu jua kerjakan/itulah jalan membetuli insan..."

Mengenali jati diri adalah ajaran semua tradisi sufistik, karena itu berasal dari sabda nabi saw.: man arafa nafsahu faqod arafa rabbahu..$^{32}$ Apabila pengenalan diri dan Tuhan ini benar maka manusia akan melihat semesta alam ini adalah tajalli Tuhan. Kebencian menjadi sirna, cinta menjadi tumbuh. Tidak ada lagi hasrat untuk memusuhi dan menyalahkan. ${ }^{33}$ Yang ada hanya hasrat untuk saling memberi, menghormati, dan menyayangi. Semua keragaman adalah tajalli dari Yang Maha Tunggal, Allah swt. Hamzah Fansuri dalam syairnya, Sunan Kalijaga dalam seni dakwahnya, adalah teladan manusia yang mengenali diri dan Tuhan dengan baik.

Secara sosiologis, realitas keragaman ini disebabkan status inheren manusia sebagai makhluk berfikir.Manusia bebas mengaktualisasikan dirinya,sehingga pluralitas lahir otomatis, seperti perbedaan ideologi, agama, bahasa, adat, bangsa, budaya, dan pandangan hidup. Tapi, tidak semua keberagaman sosiologis ini merupakan hasil olahakal pikiran, tetapi juga sering kali lahir dari kepentingan hawa nafsu yang destruktif. Manusia seing kehilangan kontrol atas hawa nafsu ini. Sufisme Islam, yaitu aspek Islam yang menekankan pada pendidikan akhlak, berurusan secara intensdengan upaya-upaya mengendalikan hawa nafsu ini.

Salah satu contoh, Imam Al-Ghazali, salah satu tokoh sufi besar dalam aliran Sunni, menyediakan dua dari empat jilid kitab Ihya' Ulumiddin untuk menjelaskan persoalan akhlak dan kontrol atas nafsu. Jilid pertama kitab Ihya' ini, al-Ghazali menjelaskan tentang amal ibadah vertikal, yaitu 113.

${ }^{31}$ Mark J. Sedgwick, Sufism: the Essentials (New York: Oxford University Press, 2003),

${ }^{32}$ Abu Bakar Muhammad bin Abdullah Ibnul Arabi, Ahkam al-Quran, jilid 2 (Beirut: Dar al-Kutub al-Ilmiah, 2003), 35. Concepts.

33 Toshihiko Izutsu, Sufism and Taoism: A Comparative Study of Key Philosophical 
hubungan manusia dengan Tuhan. Jilid kedua kitab Ihya' berbicara tentang amal horizontal, yaitu hukum fikhiyah dan aturan-aturan hukum fikih. Tetapi, jilid ketiga dan keempat, al-Ghazali menekankan tentang akhlak atau moralitas yang baik dan yang buruk. Secara persentasi dapat dikatakan, tema akhlak adalah separuh sendiri dibanding dua dimensi lainnya. ${ }^{34}$

Moralitas yang baik mudah dinodai oleh rasa suka pada dunia. Sufisme sering kali mengatakan bahwa cinta dunia adalah sumber kerusakan. Salah satu contoh cinta dunia adalah perebutan harta, sumber daya alam, kekuasaan, dan persaingan pengetahuan yang berorientasi pada kecintaan akan duniawi. Perang, permusuhan, kebencian, adalah efek yang lahir dari cinta duniawi ini. Sehingga kehadiran orang lain terasa bagai ancaman bagi eksistensi dirinya. Salah satu pilihan terbaik untuk mengatasi ancaman adalah memerangi dan membunuh, meneror dan menghabisi. ${ }^{35}$

Spirit Islam Sufistik adalah kebalikan dari ajaran materialis. Pengajaran tentang sunnatullah, pluralitas, kerukunan, dan tidak berambisi duniawi adalah dasar-dasar yang hendak ditanamkan oleh sufisme. Kedamaian dan perdamaianadalah konsekuensi saja dari jiwa luhur yang sudah terbentuk mapan. ${ }^{36}$ Selama moralitas dan akhlak luhur tertanam maka Islam terasa sebagai rahmatan lil'alamin. Yaitu, Islam sebagai agama yang membawa rahmat bagi sekalian alam. Allah swt berfirman: "Dan Tiadalah Kami mengutus kamu, melainkan untuk (menjadi) rahmat bagi semesta alam."( Qs. al- Anbiya': 107)

Rahmat yang dijanjikan Islam ini bermakna adanya kedamaian yang memiliki dua implikasi. Pertama, kedamaian bukanlah sesuatu yang hadir tanpa keterlibatan manusia. Kedamaian akan menjadi realitas kalau manusia berperan aktif dalam mengaktualisasikan cita-cita Islam. Kedua, kehidupan damai terbuka kepada semua individu, komunitas, ras, pemeluk agama, dan bangsa yang mendambakannya. Kedamaian universal ini dipahami dalam konteks tidak ada perang, teror, konflik dan kekerasan. Perdamaian akan tercipta ketika individu memiliki rasa damai dalam batinnya, memiliki kemampuan mengontrol emosi dan pikirannya, agar tidak merugikan orang lain dan memicu konflik terbuka.

${ }^{34}$ Muhammad bin Muhammad al-Ghazali, Ihya' Ulumiddin (Aleppo: Maktabah Ma'had al-Turats, 2001).

${ }^{35}$ Ibrahim ib Abdul Aziz al-Najid, Bayan al-Huda min al-Dhalal fi al-Radd ala Shahib alIghlal, jilid 1 (Kairo: Mathba' ah al-Salafiyah, 1368), 556-57.

36 A.J. Berry, Sufism: An Account of the Mystics of Islam. 
Perdamaian adalah konsep dan cara pandang yang positif terhadap diri maupun orang lain. Namun, bagi sebagian kalangan, pemahaman diatas tidak memadai dalam menjelaskan berbagai macam konflik kekerasan. Seorang feminis dan aktifis perdamaian dari Kanada, Ursula Franklin, berpendapat bahwa damai bukan hanya sekedar tidak adanya perang, tetapi damai juga terciptanya keadilan dan hilangnya ketakutan dalam diri individu dan masyarakat. Ketakutan dapat saja berupa rasa tidak aman karena faktor ekonomi, sosial, politik. Misalnya, takut tidak mempunyai pekerjaan atau tempat tinggal yang layak. ${ }^{37}$

Para ahli dan praktisi resolusi konflik (conflict resolution) memahami damai bukan hanya bebas dari peperangan (absence of war) namun juga mencakup adanya keadilan ekonomi, keadilan sosial dan budaya, serta bebas daridiskriminasi ras, kelas, gender dan agama ${ }^{38}$. Tujuannya adalah membangun masyarakat yang kondusif,menyelesaikan konflik secara damai dan beradab. Cita-cita ini diwujudkan dengan membekali individu atau kelompok dengan pengetahuan, kecakapan, dan pola hidup damai, sehingga damai bukan hanya tujuan tapi juga proses. ${ }^{39}$

\section{E. Humanisme Sufistik}

Tujuan pokok pendidikan akhlak pada dasarnya adalah agar setiap muslim berbudi pekerti yang luhur, bertingkah laku, berperangai atau beradat-istiadat yang baik sesuai dengan ajaran Islam. Ibadah-ibadah inti dalam Islam memiliki tujuan pembinaan akhlak mulia. Misalnya, shalat bertujuan mencegah seseorang dari melakukan perbuatan-perbuatan tercela; zakat disamping bertujuan menyucikan harta juga bertujuan menyucikan diri dengan memupuk kepribadian mulia cara membantu sesama; puasa bertujuan mendidik diri untuk menahan diri dari berbagai syahwat. Membentuk kepribadian seorang muslim yang berakhlak mulia, baik secara lahiriyah maupun batiniah, adalah utjuan utama pendidikan akhlak. ${ }^{40}$

${ }^{37}$ Rosalind Boyd, "Locating Gender in Approaches to Human Security: An Introduction," dalam Rosalind Boyd (ed.), The Search for Lasting Peace: Critical Perspective on Gender-Responsive Human Security (USA: Ashgate Publishing, 2014), 1.

${ }^{38}$ Mark J. Sedgwick, Sufism: the Essentials.

${ }^{39}$ Andres Solimano, Prevention and Insurance of Conflict and Terrorism: Issue and Evidence for Latin America, (Santiago: United Nations Publication, 2003), 8-9.

${ }^{40}$ Sehat Sultoni Dalimunthe, Filsafat Pendidikan Akhlak (Yogyakarta: Deepublish, 2016), 36. 
Sampai saat ini, tasawuf atau sufisme masih dicitrakan sebagai disiplin ilmu yang bersifat personal. Capaian-capain kebenaran yang disingkap bersifat subyektif, sehingga tasawuf dinilai tidak cukup peka terhadap persoalan sosial. Kaum sufi dianggap orang-orang yang egois, selalu beradu mesra dengan Tuhan, dan mengabaikan masyarakatnya. Sementara lingkungan, problem sosial, adalah realitas lain, dimana kaum sufi seolah-olah berada jauh di luar itu. Citra demikian memang harus diakui sebagai salah satu segmen sufistik yang memperagakan praktek sufisme ekslusif. Tentu, bukan ini yang dimaksud dari sufisme itu sendiri dalam konteks dan pengertiannya yang luas. Sufisme memiliki ajaran-ajaran yang sangat berkaitan dengan kehidupan konkrit, yang menata hubungan antar sesama manusia. ${ }^{41}$

Hubungan tasawuf dengan fenomena sosial yang menyangkut humanisme adalah bentuk perwujudan ihsan, yang berarti kesadaran adanya komunikasi seorang hamba dengan Tuhan. Konsep Ihsan adalah kondisi dimana manusia harus selalu merasakan kehadiran Tuhan di setiap kondisi lahir maupun batinnya. ${ }^{42}$ Kondisi lain dari seorang pelaku Ihsan (muhsin) adalah zuhud, yang berarti meninggalkan kecintaan pada materi, dan bukan berarti tidak memiliki materi. Zuhud lebih menyangkut persoalan ikatan hati pada materi, kualitas hati yang tidak lagi mengejar materi sebagai tujuan utama. Di awal telah dijelaskan, cinta dunia/materi adalah pangkal segala bentuk keburukan. Seorang muhsin pasti zuhud ${ }^{43}$.

Citra negatif lain tentang sufisme adalah bahwa sufisme cenderung diposisikan sebagai kultur spiritual (spiritual culture), sehingga dianggap tidak akan mampu menyelesaikan persoalan sosial. Kebenaran yang dicapai kaum sufi adalah kebenaran subyektif. ${ }^{44}$ Padahal, sufisme memiliki jenis pengetahuan yang disebut pengetahuan irfani, yaitu pengetahuan dan kebijaksanaan abadi,suatu anugerah langsung dari Tuhan..$^{45}$ Olahjiwa (riyadlah) merupakan bagian paling prinsip irfani dalam tradisi

${ }^{41}$ Said Aqil Siroj, Tasawuf Sebagai Kritik Sosial: Mengedepankan Islam sebagai Inspirasi bukan Aspirasi (Bandung: Mizan, 2006).

${ }_{42}$ Muhammad A.S. Hikam, Demokrasi dan Civil Society (Jakarta: PT. Pustaka Lembaga Penelitian, Pendidikan, dan Penerangan Ekonomi-LP3ES Indonesia, 1996), 39. Concepts.

${ }^{43}$ Toshihiko Izutsu, Sufism and Taoism: A Comparative Study of Key Philosophical

${ }^{44}$ Moeflich Hasbullah, Islam dan Transformasi Masyarakat Nusantara: Kajian Sosiologis Sejarah Indonesia (Depok: Kencana, t.t.), 182.

${ }^{45}$ Titus Burckhardt, Introduction to Sufi Doctrine. 
sufistik. Riyadhal adalah metode untuk mencapai tingkat "penyingkapan (kasyf)",dimana kebenaran dianugerahkan langsung oleh Tuhan kepada hamba-Nya.

Tradisi sufistik jauh lebih humanis daripada disiplin pengetahuan positivistik-empiris. Dalam prakteknya, sufisme merupakan satu bentuk potensi universal manusia dalam memenuhi kebutuhan pokok kemanusiaannya, yaitu aspek spiritual dan batin. Akal rasional dan tubuh material memiliki tuntutan kebutuhan yang berbeda dari tuntutan kebutuhan spiritualitas manusia. Karenanya, problem kemanusiaan tidak cukup diselesaikan dengan pendekatan rasional-inderawi, tetapi komponen spiritualitas juga dibutuhkan. Sufisme dengan begitu adalah komponen pelengkap humanisme dalam pengertiannya yang luas. ${ }^{46}$

Sufisme bukan semata seruan untuk menghayati ritual keagamaan belaka melainkan juga seruan cinta. Ibadah mahdah (shalat, dzikir, puasa, etc.) maupun ibadah muamalah (jual beli, pernikahan, zakat, etc) belum sempurna bila hanya memenuhi syarat-syarat yang ditetapkan dalam ilmu fikih. Semua ibadah harus didekati dengan aturan sufistik, seperti tulus, ikhlas, tidak riya', tidak pamer, demi meraih ridho Allah, dan lainnya. ${ }^{47}$

Pada awal kemunculannya, sufis memengajarkan cinta sebagai spirit praktek hidup kaum sufi. Sufisme pada awalnya adalah bentuk rasa takut seorang hamba melakukan dosa, seperti di era para Sahabat Nabi dan Tabi'ien. Pada perkembangan berikutnya, sufisme menjelma menjadi praktek rasa cinta terhadap Tuhan.Mengerjakan perintah Allah dan menjauhi larangan Allah bukan demi mencari imbalan surga dan menghindari siksa neraka, melainkan lantaran cinta yang tulus pada Allah. Cinta menjadi ruh yang menghidupkan praktek sufistik.

Cinta dalam dunia sufi digambarkan sebagai keadaan yang dialami hati seseorang namun cukup sulit untuk diungkapkan secara verbal. Keadaan cinta seperti ini mendorong kondisi seseorang untuk mensucikan Tuhan dan mencari ridla-Nya yang luas. Pencarian ridla Tuhan tidak terkungkung oleh satu kondisi ritual peribadatan saja melainkan juga mempunyai makna yang lebih luas, hingga menyentuh problem-problem sosial kemanusiaan. Cinta pada Tuhan dapat diwujudkan dengan menolong

\footnotetext{
${ }^{46}$ Rani Anggraeni Dewi, Menjadi Manusia Holistik, (Bandung: Mizan, 2007), 168.

${ }^{47}$ Salim bin Ied al-Hilali, Ensiklopedi Larangan Menurut al-Quran dan as-Sunnah, terj. Abu Ihsan al-Atsari (Bogor: Pustaka Imam Syafii, 2005), 64-65.
} 
orang lain yang lapar dan membutuhkan pertolongan. Bahkan, membuang duri di jalan yang mengganggu perjalanan adalah praktek dari sufisme.

Sufisme yang selalu berkaitan dengan cinta berkaitan pula dengan konsep keindahan (estetika). ${ }^{48}$ Kenyataannya, cinta memang selalu bertalian dengan keindahan. Cinta itu muncul karena keindahan. Atau sebaliknya,lantaran jatuh cinta maka keindahan terlahir. Keindahan dan cinta berpilin hingga sulit dipisahkan. Dari sini, seorang sufi dapat digambarkan sebagai individu yang memiliki hati yang lembut, budi pekerti yang luhur, sikap yang halus dan penuh cinta dan keindahan.

Bentuk keindahan tertinggi dalam sufisme adalah perjumpaan dengan Tuhan. Pertemuan tersebut terjadi pada hati yang suci. Dalam pengertian yang lebih membumi, keindahan tertinggi terletak di dalam hati yang suci. Keindahan hati ini dalam tradisi sufistik disebut "ihsan". Secara terminilogis, Ihsan mempunyai banyak makna,seperti indah, baik, dan sempurna. Makna ini tidak saja terjadi dalam konteks hubungan internal-vertikal antaramanusia dan Tuhan melainkan juga termanifestasi dalam hubungan sesama manusia lewat etika dan moralitas yang luhur. Ibnu Arabi mengatakan, ihsan dan keindahan adalah faktor penyebab bagi kemunculan cinta itu sendiri. ${ }^{49}$

Keindahan tanpa batas yang diraih kaum sufi menandai bahwa hubungan manusia tidak terbatas dengan Tuhan semata, tetapi juga berkaitan erat dengan hubungan antar sesama. Bahkan, manusia dan alam semesta ini adalah tajalli atau mazhahir Allah swt. Cinta dan keindahan menjadi aspek paling signifikan dan tali simpul dalam merumuskan pengertian sufisme. Karena cinta dan keindahan memenuhi lubuk hati seseorang, karena manusia dan jagad semesta adalah manifesasi Tuhan, maka mencintai sesama, memperjuangkan perdamaian, adalah tujuan utama sufisme.

\section{F. Spiritualitas Cinta Agama-agama}

Agama adalah dakwah dan pendidikan. Setiap agama memiliki ajaran yang serupa dengan sufisme Islam. Dengan begitu, setiap agama

${ }^{48}$ Ahmad al-Witari, Fiqh al-Wujud: Muqaddamah fi al-Mafhum al-Qurani li al-Hayah wa al-Mawt wa al-Jannah, (Al-Manhal, 2011), 24.

${ }^{49}$ Quito R. Motinggo, Keajaiban Cinta: Membuat Hidup Lebih Berenergi dan Dinamis, (Bandung: Hikmah, 2005), 12-13. 
memiliki potensi yang sama untuk mendorong umat beragama berwawasan perdamaian. Agama adalah institusi paling efektif untuk mengajak para pemeluknya berpikir pluralis, demokratis, menjunjung hak asasi manusia, dan hidup berdampingan satu sama lain.Dalam konteks umat muslim, sufisme bisa ditransfer ke dalam ranah sturktur sosial yang mejemuk. Dalam artian, ajaran cinta dan perdamaian sufisme memungkinkan manifes dan membentuk struktur sosial yang mendukung program perdamaian. Kedamaian dan perdamaian terbuka lewat pintu sufismse. Ajaran cinta kasih dalam setiap agama inilah yang potensial untuk mengantarkan umat beragama untuk saling menghargai, menghormati, dan rukun berdampingan.

Agama-agama semit seperti Yahudi, Kristen dan Islam memiliki ajaran cinta kasih antar sesama. Dalam Yahudi ada doktrin untuk tidak membunuh nyawa manusia yang tidak berdoa. Dengan tegas dikatakan bahwa, doktrin Yahudi untuk mencintai Tuhan sepenuh hati adalah ajaran inti. Mencintai Tuhan dengan segenap hati, perasaaan, pikiran, daya dan upaya harus dicurahkan hanya kepada Tuhan. ${ }^{50}$

Dalam Islam, Muhammad membawa agama Islam sebagai rahmatan lil alamin. Islam sebagai agama damai tidak asing dalam konteks diskusi akademik kita, sekalipun terkadang ada banyak pakar Barat memandang beberapa doktrin Islam tentang cinta sangat dekat dengan tradisi yang berkembang di Barat, khususnya dalam tradisi Yunan Kuno, ajaran Neoplatonik. ${ }^{51}$ Pandangan ini hanya sekedar pandangan paradigmatif dan analitik, yang coba mencari akar sufisme Islam ke tradisi yang lebih tua. Dengan kata lain, akan banyak pakar dari internal Islam yang mengatakan bahwa ajaran cinta kasih dalam Islam bersumber pada al-Quran Hadits sebagai rujukan utama agama Islam. ${ }^{52}$ Terlepas dari perdebatan ini, tiga agama semit memiliki akar doktrinal tentang cinta.

Selain agama semit, Agama Buddha juga datang untuk menebar cinta kasih dan menghilangkan penderitaan umat manusia. Tanpa cinta, dalam Buddhisme, hidup ini bagaikan neraka yang dihuni oleh Asura.

${ }^{50}$ Isaac Mayer Wise, Judaism: Its Doctrines and Duties (Washington: Office of The Israelite, 1872), 46 .

${ }^{51}$ Binyamin Abrahamov, Divine Love in Islamic Mysticism: the Teachings of al-Ghazali and al-Dabbagh (Oxon: Routledge, 2003), 56.

${ }^{52}$ Lihat kajian ilmiah dari Muhammad Sholikhin, Sufi Modern: Mewujudkan Kebahagiaan, Menghilangkan Keterasingan, (Jakarta: Elex Media Komputindo, 2013). 
Bahkan, Buddha sendiri lahir ke dunia berkat dari tindakan penuh cinta kedua orangtuanya. Setiap individu diajarkan untuk melakukan prajna, suatu pencarian jati diri ke dalam diri untuk menemukan hakikat kebuddhaan, yaitu cinta. Cinta menempati posisi penting dalam lingkungan kaum Buddhist. ${ }^{53}$

Agama Hindu meyakini semesta ini adalah penampakan Tuhan. Hindu memiliki ajaran tentang Bhakti, yang berarti bahwa manusia tidak saja harus mencintai Tuhan tetapi juga mencintai seluruh dunia, termasuk mencintai musuh-musuh yang membenci orang bersangkutan. ${ }^{54}$ Ajaran Bhakti adalah ajaran luhur Hinduisme, dimana cinta akan menghapus seluruh kebencian, memperjuangkan perdamaian.

Ajaran cinta kasih ini yang terdapat pada ajaran seluruh agama adalah ajaran universal. ${ }^{55}$ Sehingga,peluang menciptakan perdamaian dunia, atau setidaknya kesadaran akan pentingnya perdamaian, sangat terbuka besar dengan menjadikan ajaran cinta ini sebagai penghapus sekatsekat perbedaan.Ajaran cinta kasih menjadi simpul kesamaan universal yang dimiliki oleh setiap agama ${ }^{56}$.

Persepsi negatif yang sering kali dimiliki sebagian muslim terhadap agama dan umat agama lain tidak perlu terjadi. ${ }^{57}$ Aspek persamaan dalam setiap agama dapat menjadi aspek perekat dari perbedaan yang ada. Apabila sufisme terbuka menjadi alternatif paling potensial untuk memediasiperdamaian dalam hubungan antar umat beragama, maka perbedaan parsial tidak perlu diungkit.

Secara teknik, ajaran cinta sebagai inti sufisme Islam bisa diterjemahkan ke dalam kehidupan sehari-hari.Penerjemahan ini disebut

${ }^{53}$ Wayne Cristaudo dan Gregory Kaplan, Love in the Religions of the World, (UK: Cambridge Scholars Publishing, 2011), 77.

${ }^{54}$ Klaus K. Klostermaier, A Survey of Hinduism, 3 ed. (New York: SUNY Press, 2007), 187.

55 Yudit Kornberg Greenberg, Encyclopedia of Love in World Religions, vol. 1 (California: ACB-CLIO, 2007), 122.

56 Muhammad Sholikhin, Sufi Modern: Mewujudkan Kebahagiaan, Menghilangkan Keterasingan, (Jakarta: Elex Media Komputindo, 2013).

57 Thomas Matyok, Hamdesa Tuso dan Maureeen Flaherty melakukan kajian mendalam tentang sinergi antar tradisi keagamaan dengan pendekatan multidimensi. Dalam kajian ini, mereka membuktikan bahwa agama tidak saja memiliki peran sentral dalam proses pembentukan perdamaian dan rekonsiliasi, tetapi juga terlibat dalam perpecahan dan konflik. Lihat Thomas Matyok, dkk., Peace on Earth: the Role of Religion in Peace and Conflict Studies (Lexington Books, 2013). 
sebagai maqomat. Ada beberapa jenis maqomat yang dikenal dalam dunia sufi, di antaranya:

Pertama,taubat..$^{58}$ Secara umum, taubat diartikan sebagai usaha manusia meninggalkan perbuatan buruk, menyesali secara serius dan mendalam, serta komitmen untuk tidak mengulanginya kembali.

Kedua, wara', ${ }^{59}$ yaitu menjauhkan diri dari hal-hal yang berbau subhat, sesuatu yang statusnya tidak jelas, baik secara lahir dan batin. Ketidakpastian hukum adalah perkara yang paling dijauhi. Sebab, dalam sufisme, subhat lebih mendekatkan pada haram, dan otomatis akan menyebabkan manusia masuk ke dalam neraka.

Ketiga, zuhud, ${ }^{60}$ yaitu tidak mengutamakan kehidupan dunia atas kehidupan akhirat, memutus tali kecintaan akan hal-hal duniawi. Hati seorang salik, penempuh jalan Tuhan, hanya terisi oleh cinta pada Allah. Tidak pernah sedetikpun melirik pada keindahan dan gemerlap duniawi. Bahkan, kecintaan pada dunia adalah ra's al-khabaits, pangkal segala jenis keburukan, kejahatan, dan problem.

Keempat, faqir, ${ }^{61}$ yaitu mengosongkan seluruh pikiran dan hati dari kehidupan masa kini dan masa depan, dan tidak menghendaki sesuatu apapun kecuali Alah swt. Berbeda dengan zuhud, faqir lebih menekankan kebutuhan dan kebergantungan pada Allah. Apabila zuhud hanya memutus tali cinta pada dunia, maka faqir menekankan aspek kebergantungan pada Allah swt.

Kelima, sabar, ${ }^{62}$ yaitu sikap hati yang selalu menerima segala bencana dengan laku sopan dan rela, tidak marah dan lapang dada, ridha dan ikhlas. Kesabaran adalah situasi batin manusia saat dirinya tidak lagi kecewa pada peristiwa eksternal apapun yang terjadi, dimana lumrahnya akan menyebabkan kekecewaan. Sabar adalah pintu kesadaran yang

${ }^{58}$ Ada banyak macam taubat. Taubatnya Nabi, yaitu Allah menghilangkan sifat lupa dari Nabi dan membuatnya selalu ingat pada Allah. Taubatnya kaum Anshar dan Muhajiri, yaitu bertaubat dari mengerjakan maksiat dan menggantinya dengan ibadah Abu Bakar Muhammad bin Abdullah Ibnul Arabi, Ahkam al-Quran, 595.

${ }^{59}$ Taqiyuddin Ahmad Ibnu Taimiyah al-Harrani, Majmu'ah al-Fatawa, jilid 36 (Dar al-Wafa, 2005), 679 .

${ }^{60}$ Abu Bakar Ahmad bin al-Husain al-Baihaqi, Kitab Al-Zuhdu al-Kabir (Beirut: Dar al-Jinan, 1987), 63-73.

${ }^{61}$ Muhammad Hamid, al-Mutasyawwif (Dar al-Muharrir al-Adabi, 2018), 415.

${ }^{62}$ Amad Zaki al-Barudi, Asma Allah al-Husna wa Sifatihi al-Ulya min Kutub Ibn alQayyim (al-Maktabah al-Tawfiqiyah, t.t.), 288-89. 
membuka pikiran bahwa segala peristiwa yang sudah terjadi merupakan rencana Tuhan yang mengandung hikmah kebaikan, sekalipun belum bisa dimengerti oleh nalar manusia.

Keenam,tawakkal, ${ }^{63}$ yaitu percaya bahwa segala apa yang terjadi telah ditentukan oleh takdir Tuhan. Dalam tawakal terdapat optimisme bahwa hari esok akan ada ganti yang lebih baik. Tawakal menjadi tameng manusia dari gempuran perasaan putus asa, hilang harapan, dan tidak semangat menatap hidup. Tawakal adalah motor yang kembali menggerakkan orang-orang yang secara sosiologis maupun psikologis terkagegorikan sebagai orang yang kalah oleh kehidupan.

Ketujuh, ridla, ${ }^{64}$ yakni hilangnya rasa ketidaksenangan dalam hati, sehingga hatinya hanya terisi oleh kegembiraan dan sukacita. Apapun yang terjadi, walaupun tidak sesuai dengan harapan dan rencana, walaupun bertolakbelakangan dari target yang hendak dicapai, hati yang ridha akan tetap bahagia. Bahkan, sekalipun ditimpa bencana berkali-kali, hati Salikyang dipenuhi keridhaan akan takdir Tuhan akan tetap bahagia. Ia tidak akan memandang bencana sebagai bencana.

Maqomat di atas adalah translasi dari cinta yang menjadi inti dari ajaran sufisme Islam. Apabila kita mencintai Allah dengan betulbetul cinta maka realitas semesta adalah perwujudkan cinta. Karenanya, bagaimana mungkin seorang salik akan kecewa pada kenyataan hidup bila keyakinannya mengarahkan dia untuk berpikir tentang hidup sebagai manifestasi cinta ilahiah. Seorang salik yang memiliki maqomat ini, memiliki cinta sejati yang ilahiah, dia akan jauh dari kebencian, jauh dari permusuhan dan perpecahan, dan mustahil menyelenggarakan perang di pentas sejarah manusia.

\section{G. Simpulan}

Pendekatan sufistik dalam pendidikan Islam adalah jawaban alternatif dalam merespon fenomena kekerasan, terorisme, dan konflik yang manifes dalam beragam rupa. Sufisme Islam adalah wajah Islam yang penuh cinta dan damai. Spirit ini juga terdapat dalam agama-gama besar dunia, sehingga memungkinkan kerjasama lintas keyakinan untuk membangun dunia yang lebih damai dan beradab.

\footnotetext{
${ }^{63}$ Muhammad Sholih Munjid, al-Tawakkul (A'mal al-Qulub, 2009), 9-11.

${ }^{64}$ Muhammad al-Rawi, al-Ridha (Mesir: Maktabah al-Akademiqoh, 2009), 5-9.
} 
Sufisme Islam tidak saja mengajarkan cinta tetapi juga semangat humanisme universal. Humanisme religius, atau nilai-nilai humanis yang diangkat dari ajaran agama, adalah alternatif terhadap humanisme sekuler. Tentu saja ini adalah wacana menarik untuk memberikan jawaban pada dunia kontemporer yang tak kunjung sepi dari perang dan teror. Setiap agama, bukan saja Islam, mengajarkan cinta kasih, dan inilah cinta kasih yang menginspirasi humanisme religius.

Alhasil, optimisme bahwa pendekatan sufistik terhadap pendidikan Islam berwawasan perdamaian, menemukan momentumnya. Output pendidikan Islam yang mengadopsi ajaran-ajaran sufistik diharapkan mampu berkontribusi besar terhadap upaya-upaya perdamaian dan penciptaan kehidupan manusia yang lebih beradab, humanis, pluralis, dan tentu saja agamis[.]

\section{REFERENSI}

Abu Bakar Ahmad bin al-Husain al-Baihaqi. Kitab Al-Zuhdu al-Kabir. Beirut: Dar al-Jinan, 1987.

Abu Bakar Muhammad bin Abdullah Ibnul Arabi. Ahkam al-Quran. jilid 2. Beirut: Dar al-Kutub al-Ilmiah, 2003.

Ahmad al-Witari. Figh al-Wujud: Muqaddamah fi al-Mafhum al-Qurani li alHayah wa al-Mawt wa al-Jannah,. Al-Manhal, 2011.

Ahmad Thib ibn al-Basyir. Kitab al-Hikam al-Musamma an-Nafs al-Rahmani fi al-Thur al-Insani. Beirut: Dar al-Kutub al-Ilmiah, 2014.

A.J. Berry. Sufism: An Account of the Mystics of Islam. Oxon: Routledge, 2013.

Al-Kaf, Idrus. "Pemikiran Sufistik Syaikh Umar Ibn Al-Fâridh dalam Dîwân Ibn Al-Fâridh" 20, no. 1 (2014): 23.

Amad Zaki al-Barudi. Asma Allah al-Husna wa Sifatihi al-Ulya min Kutub Ibn al-Qayyim. al-Maktabah al-Tawfiqiyah, t.t.

Amanullah Halim. Buku Putih Kaum Jihadis: Menangkal Ekstrimisme Agama dan Fenomena Pengafiran. Tangerang: Lentara Hati, 2015.

Andres Solimano. Prevention and Insurance of Conflict and Terrorism: Issue and Evidence for Latin America,. Santiago: United Nations Publication, 2003. 
Asghar Ali Enginer. Islam dan Teologi Pembebasan. Yogyakarta: Bentang Pustaka, 2000.

Azyumardi Azra. Islam in the Indonesian World an Account of Institutional Formation. Bandung: Mizan, 2006.

Binyamin Abrahamov. Divine Love in Islamic Mysticism: the Teachings of alGhazali and al-Dabbagh. Oxon: Routledge, 2003.

E. O'Ballance. Islamic Fundamentalist Terrorism. The Iranian Connection, 1979.

Harun Nasution,. "Teologi Islam; Aliran-aliran Sejarah Analisa Perbandingan." Jakarta: UI Press, 1986.

Ibrahim ib Abdul Aziz al-Najid. Bayan al-Huda min al-Dhalal fi al-Radd ala Shahib al-Ighlal. jilid 1. Kairo: Mathba'ah al-Salafiyah, 1368.

Isaac Mayer Wise. Judaism: Its Doctrines and Duties. Washington: Office of The Israelite, 1872.

Jannah, Fathul. "PENDIDIKAN ISLAM DALAM SISTEM PENDIDIKAN NASIONAL" 13, no. 2 (2013): 13.

Jean Louis Michon, dan Roger Gaetani. Sufism: Love \& Wisdom. Indiana: Worl Wisdom Inc., 2006.

Jimly As-Shiddiqie. Bang Imad: Pemikiran dan Gerakan Dakwahnya,. Jakarta: Gema Insani Press, 2002.

Khaled Abou El Fadhl. Selamatkan Islam dari Muslim Puritan. Jakarta: Serambi, 2006.

Klaus K. Klostermaier. A Survey of Hinduism. 3 ed. New York: SUNY Press, 2007.

Madarzuki Wahid dan Rumi. Figh Madzhab Negara: Kritik atas Politik Hukum Islam di Indonesia. Yogyakarta: LKiS, 2011.

Mamadou Diouf. Tolerance, Democracy, and Sufis in Senegal,. New York: Columbia University Pres, 2013.

Mani' ibnu Hammad al-Juhni. al-Mawsu'ah al-Muyassarah fi al-Adyan wa alMadzahib wa al-Ahzab al-Mu'ashirah. 4 ed. Riyadh: Dar al-Nadwah alAlamiyah, 1420.

Mark J. Sedgwick. Sufism: the Essentials. New York: Oxford University Press, 2003. 
Moch Eksan, dan Kiai Kelana. Biografi Kiai Muchith Muzadi. Yogyakarta: LKIS, 2000.

Moeflich Hasbullah. Islam dan Transformasi Masyarakat Nusantara: Kajian Sosiologis Sejarah Indonesia. Depok: Kencana, t.t.

Muhammad al-Rawi. al-Ridha. Mesir: Maktabah al-Akademiqoh, 2009.

Muhammad A.S. Hikam. Demokrasi dan Civil Society. Jakarta: PT. Pustaka Lembaga Penelitian, Pendidikan, dan Penerangan Ekonomi-LP3ES Indonesia, 1996.

Muhammad bin Muhammad al-Ghazali. Ihya' Ulumiddin. Aleppo: Maktabah Ma'had al-Turats, 2001.

Muhammad Hamid. al-Mutasyawwif. Dar al-Muharrir al-Adabi, 2018.

Muhammad Hisyam Kabbani. Tasawuf dan Ihsan, terj. Zaimul Am. Jakarta: Serambi, 2007.

Muhammad Nawawi al-Bantani. al-Futuhat al-Madaniyyah (T.Th.), t.t.

Muhammad Sholih Munjid. al-Tawakkul. A'mal al-Qulub, 2009.

Muhammad Sholikhin, Sufi Modern: Mewujudkan Kebahagiaan, Menghilangkan Keterasingan, (Jakarta: Elex Media Komputindo, 2013), t.t.

Nathanael Emmons and Jacob Ide. Systematic Theology. Bonston: Crocker\& Brewster, 1842.

N.K. Singh. A Religion of Peace. Global Vision, 2002.

Quito R. Motinggo. Keajaiban Cinta: Membuat Hidup Lebih Berenergi dan Dinamis,. Bandung: Hikmah, 2005.

Rani Anggraeni Dewi. Menjadi Manusia Holistik, Bandung: Mizan, 2007.

Rosalind Boyd. "Locating Gender in Approaches to Human Security: An Introduction," dalam Rosalind Boyd (ed.), The Search for Lasting Peace: Critical Perspective on Gender-Responsive Human Security. USA: Ashgate Publishing, 2014.

Said Aqil Siroj. Tasawuf Sebagai Kritik Sosial: Mengedepankan Islam sebagai Inspirasi bukan Aspirasi. Bandung: Mizan, 2006.

Salim bin Ied al-Hilali. Ensiklopedi Larangan Menurut al-Quran dan as-Sunnah, terj. Abu Ihsan al-Atsari. Bogor: Pustaka Imam Syafii, 2005.

Sayyed Hossein Nasr. The Garden of Truth. Bandung: Mizan, 2010. 
Sehat Sultoni Dalimunthe. Filsafat Pendidikan Akhlak. Yogyakarta: Deepublish, 2016.

Sokhi Huda. Tasawuf Kultural: Fenomena Shalawat Wahidiyah. Yogyakarta: LKIS, 2008.

Taqiyuddin Ahmad Ibnu Taimiyah al-Harrani. Majmu'ah al-Fatawa. Jilid 36. Dar al-Wafa, 2005.

Thomas Matyok, dkk. Peace on Earth: the Role of Religion in Peace and Conflict Studies. Lexington Books, 2013.

Titus Burckhardt. Introduction to Sufi Doctrine. Indiana: World Wisdom, Inc., 2008.

Toshihiko Izutsu. Sufism and Taoism: A Comparative Study of Key Philosophical Concepts. California: University of California Press, 1984.

Tudor Rose. Agree to Differ. France: UNESCO Publishing, 2015.

Wayne Cristaudo dan Gregory Kaplan. Love in the Religions of the World, UK: Cambridge Scholars Publishing, 2011.

Wolfram Weisse, dan Inga Niehaus. Muslim School and Education in Europe and South Africa,. Munster: Waxmann, 2011.

Yudit Kornberg Greenberg. Encyclopedia of Love in World Religions. Vol. 1. California: ACB-CLIO, 2007.

Yusuf Ahmad Muhammad al-Badawi. Maqashid al-Syariah inda Ibn Taymiyah. Yordania: Dar al-Nafais, 1999. 